\title{
Data deposit in a CKAN repository: a Dublin Core-based simplified workflow
}

Yulia Karimova, João Aguiar Castro, Cristina Ribeiro

INESC TEC, Faculdade de Engenharia da Universidade do Porto

C 8 MPETE 2020
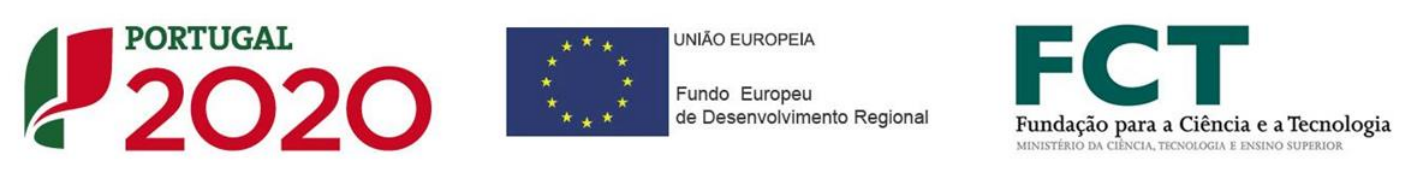
Institute for Systems and Computer Engineering, Technology and Science

Research / Clusters

- Computer Science

- Industry and Innovation

- Networked Intelligent Systems

- Power and Energy

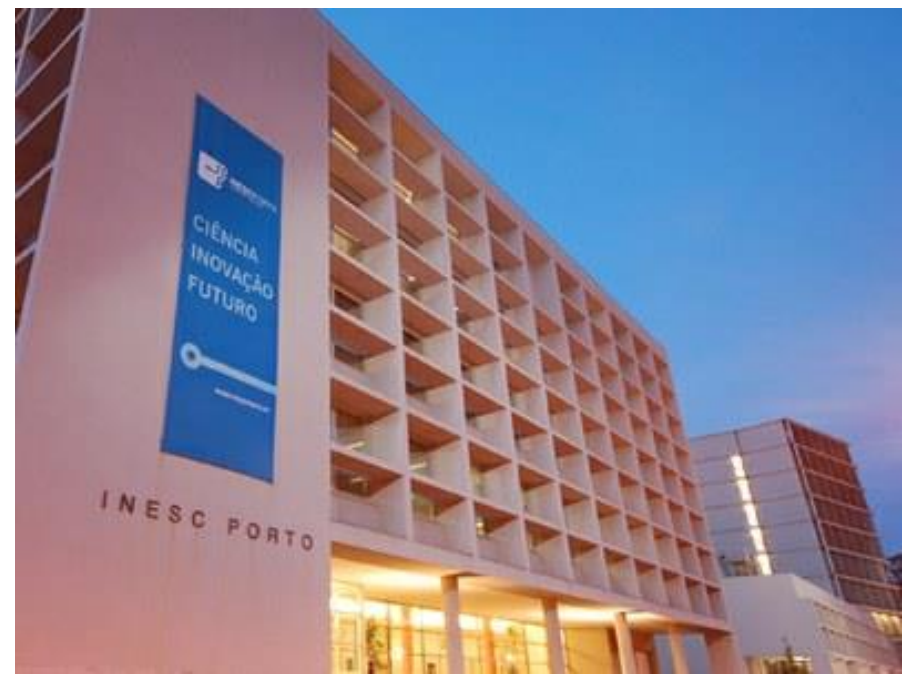




\section{Data repository at INESC TEC - Motivation}

Engage researchers in RDM through data description, using Dublin Core

1) Practical when assessment of requirements is not possible;

2) Easier for researchers to grasp concepts behind Dublin Core descriptors

Many datasets from closed projects will not reach publication stage without an agile deposit process 


\section{INESC TEC data repository}

\section{OJ INESCTEC}

\section{Datasets}

About

Search

a

Welcome to the INESC TEC research data repository.

This data repository showcases datasets produced or used by INESC TEC researchers and their partners. It is an embodiment of our institutional commitment to Open Data in research.

\section{Of INESCTEC}

Research Data

Repository

\section{This is a featured section}

CS: Computer Science

The Computer Science Cluster mission is to..

Radon concentration (Bq.m-3) from INESC TEC station (Porto). Ongoing, updated.

The dataset consists on measurements every 6 -hours of radon concentration on the roof of INESC TEC main building ...

Atmospheric electric field from INESC TEC station (Porto). Ongoing, updated ...

The dataset consists on 1-min measurements of the atmospheric electric field by a C 110 field mill installed on the.

\section{Search data}

E.g. environment

Popular tags environmental radio... atmosphere radon

INESC TEC

The Institute for Systems and Computer

Radon concentration (Bq.m-3) from INESC TEC station (Porto). Ongoing, updated.

The dataset consists on measurements every 6 -hours of radon concentration on the roof of INESC TEC main building...

Atmospheric electric field from INESC TEC station (Porto). Ongoing, updated ...

The dataset consists on 1-min measurements of the atmospheric electric field by a CS110 field mill installed on the.

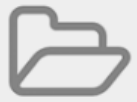

CS: Computer

Science

The Computer Science

Cluster mission is to

contribute to the

understanding of ...
Industry and

Innovation

The Industry and Innovation Cluster is the aggregation of

INESC TEC research.

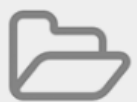

PE: Power and

Energy

The Power and Energy

Cluster aims to assure the

continuity of the worldwide
NIS: Networked Intelligent Systems

The Networked Intelligent

Systems Cluster aims to

create autonomous

networked... 


\section{INESC TEC data repository}

\section{Albergaria Fire Fighters ECG 2010}

Monitoring of Albergaria Firefighters ECG during emergency events during the summer of 2010 and correspondent event labels.

\section{Data and Resources}

\section{- SESSION-2010-06-07-01-OUTSIDE.zip}

Approximately 59 hours of ECG missions recordings of 5 Firefighters in .bdd...

\section{AlbergariaFirefighters}

\section{Additional Info}

\begin{tabular}{|l|l|}
\hline Field & Value \\
\hline Author & Joana Paiva, João Paulo Cunha \\
\hline Last Updated & 4 de Dezembro de 2018, 18:22 (UTC+00:00) \\
\hline Created & 19 de Janeiro de 2017, 13:23 (UTC+00:00) \\
\hline DOI & https://doi.org/10.25747/NPNT-P555 \\
\hline dc.Contributor & Vital Responder 1.0 team, VR2Market team \\
\hline dc.Coverage.Spatial & Albergaria \\
\hline dc.Coverage.Temporal & February-July 2010 \\
\hline
\end{tabular}

\begin{tabular}{|c|c|}
\hline dc.Date & Summer, 2010 \\
\hline dc.Format & ${ }^{*}$.bdd, * ${ }^{*}$ xls \\
\hline dc.Format.Extent & $165 \mathrm{MB}$ \\
\hline dc.Identifier & 2010_AlbergariaFFs_ECG \\
\hline dc.Publisher & INESC TEC \\
\hline dc.Relation & $\begin{array}{l}\text { Brás, S., Fernandes, J. M., \& Cunha, J. P. (2013, } \\
\text { June). ECG delineation and morphological analysis } \\
\text { for firefighters tasks differentiation. In Computer- } \\
\text { Based Medical Systems (CBMS), 2013 IEEE 26th } \\
\text { International Symposium on (pp. 516-517). IEEE. } \\
\text { ISO } 690 \text { DOI: } 10.1109 / \text { CBMS.2013.6627856; } \\
\text { Pallauf, J., Gomes, P., Brás, S., Cunha, J. P. S., \& } \\
\text { Coimbra, M. (2011, August). Associating ECG } \\
\text { features with firefighter's activities. In Engineering } \\
\text { in Medicine and Biology Society, EMBC, } 2011 \\
\text { Annual International Conference of the IEEE (pp. } \\
6009-6012) \text {. IEEE DOI: } \\
\text { 10.1109/iembs.2011.6091485 }\end{array}$ \\
\hline dc.Type & ECG data, Events labels \\
\hline
\end{tabular}




\section{Descriptors in the repository}

\begin{tabular}{|l|l|}
\hline Dataset attributes & Corresponding descriptor and vocabulary \\
\hline Availability & Visibility (CKAN), DOI \\
\hline Bibliometric data & - \\
\hline Coverage & Coverage.Temporal (Dublin Core), Coverage.Spatial (Dublin Core) \\
\hline Date & Date (Dublin Core) \\
\hline Format & Format (CKAN), Format (Dublin Core), Format.Extent (Dublin Core) \\
\hline License & License (CKAN); License (Dublin Core) \\
\hline Minimal description & $\begin{array}{l}\text { Title (CKAN), Name (CKAN), Author (CKAN), Author email (CKAN), } \\
\text { Description (CKAN), Maintainer (CKAN), Maintainer email (CKAN), } \\
\text { Type (Dublin Core), Language (Dublin Core), Publisher (Dublin Core), } \\
\text { Contributor (Dublin Core) }\end{array}$ \\
\hline Paper reference & Relation (Dublin Core) \\
\hline Project & Organization (CKAN), Group (CKAN) \\
\hline Provenance & Source (CKAN), Version (CKAN) \\
\hline Subjects & Tags (CKAN) \\
\hline
\end{tabular}




\section{Deposited datasets}

\begin{tabular}{|c|c|c|c|c|c|c|}
\hline \multirow{2}{*}{ Domain } & \multicolumn{4}{|c|}{ Datasets deposited in 2017} & \multicolumn{2}{|c|}{2018} \\
\hline & 1 trimester & 2 trimester & 3 trimester & 4 trimester & 1 trimester & 2 trimester \\
\hline $\begin{array}{l}\text { Biomedical } \\
\text { engineering }\end{array}$ & - & & & & & \\
\hline $\begin{array}{l}\text { Environmental } \\
\text { radioactivity }\end{array}$ & • & • & • & • & • & - \\
\hline Biomedicine & & • & & & - & \\
\hline Robotics & & & & & • & \\
\hline $\begin{array}{c}\text { Information } \\
\text { science }\end{array}$ & & & & & $\bullet$ & \\
\hline $\begin{array}{c}\text { Natural language } \\
\text { processing }\end{array}$ & & - & • & $\diamond$ & & \\
\hline Music streaming & • & & & & & \\
\hline $\begin{array}{c}\text { Information } \\
\text { retrieval }\end{array}$ & $\bullet$ & & $\diamond$ & & & \\
\hline
\end{tabular}

- - public datasets $\diamond-$ private datasets 


\section{Description results}

\begin{tabular}{|l|c|c|}
\hline \multicolumn{1}{|c|}{ Descriptor } & $\begin{array}{c}\text { Descriptors used } \\
\text { by researchers }\end{array}$ & $\begin{array}{c}\text { Descriptors after } \\
\text { curator feedback }\end{array}$ \\
\hline Title & 21 & 21 \\
\hline Author & 21 & 21 \\
\hline Author email & 21 & 21 \\
\hline Description & 20 & 21 \\
\hline Format & 20 & 21 \\
\hline Tags & 19 & 21 \\
\hline License & 16 & 21 \\
\hline Coverage (Temporal) & 16 & 17 \\
\hline Type & 16 & 20 \\
\hline Date & 15 & 21 \\
\hline Coverage (Spatial) & 14 & 15 \\
\hline Language & 14 & 16 \\
\hline Publisher & 12 & 21 \\
\hline Relation & 12 & 15 \\
\hline Source & 10 & 10 \\
\hline Contributor & 6 & 6 \\
\hline Format.Extent (File size) & 5 & 21 \\
\hline
\end{tabular}




\section{General conclusions}

o Metadata and descriptor concepts are not easy to understand;

o Contributor only for external parties; Author for all group members;

o More detailed metadata after data curation feedback; Title often revised. 


\section{General conclusions}

o Researchers do not want to spend much time in description;

- Inconsistent metadata will improve with controlled vocabularies (e.g. ISO 639-2);

- Curiosity about data citation and sense of awareness regarding data preservation. 


\section{Researchers feedback}

"We have used the dataset link in our papers"

"I think our data was not reused yet (or, if they were, we are not informed; It would be useful to have some idea of how many times the data was downloaded";

"At first I found it hard, but as we go it becomes much easier and simpler"

"The process itself is a bit time consuming. The choice of descriptors is not something for which we are oriented and the support of the curator is fundamental here" 


\section{Conclusions}

- A first step to involve researchers in data description;

- Different levels of RDM awareness require different approaches and flexibility;

- Experienced researchers showed greater interest - collaboration in other RDM activities, such as the development of DMPs (although expectations are not quite fulfilled);

o Metadata is still lackluster and there is a need to extend the metadata form. 